\title{
Detecção de Curtobacterium flaccumfaciens pv. flaccumfaciens em sementes de feijoeiro produzidas em Santa Catarina
}

\author{
Daniel H. Herbes ${ }^{1}$, Gustavo F. Theodoro ${ }^{2}$, Antonio C. Maringoni ${ }^{3}$, Celso A. dal Piva ${ }^{4} \&$ Lucilene de Abreu $^{1}$ \\ ${ }^{1}$ Universidade Comunitária Regional de Chapecó, Cx. Postal 747, 89809-000, Chapecó, SC, Brasil; ${ }^{2}$ Campus de Chapadão do \\ Sul, Universidade Federal de Mato Grosso do Sul, Cx. Postal 112, 79560-000, Chapadão do Sul, MS, Brasil; ${ }^{3}$ Departamento \\ de Produção Vegetal, Universidade Estadual Paulista, Cx. Postal 237, 18603-970, Botucatu, SP, Brasil; ${ }^{4}$ Empresa de Pesquisa \\ Agropecuária e Extensão Rural de Santa Catarina, Centro de Pesquisa para Agricultura Familiar, Cx. Postal 791, 89801-970, \\ Chapecó, SC, Brasil
}

Autor para correspondência: Gustavo F. Theodoro, e-mail: theodoro@nin.ufms.br

RESUMO

Foi avaliada a presença de Curtobacterium flaccumfaciens pv. flaccumfaciens em 37 amostras de sementes de feijoeiro, dos grupos preto e carioca, produzidas em municípios do Estado de Santa Catarina, nas safras 2004/2005 e 2005/2006. Para a detecção, as sementes foram maceradas e alíquotas de sua suspensão foram transferidas para o meio de cultura semi-seletivo MSCFF. A identidade dos isolados obtidos foi comprovada por meio da observação da morfologia celular, coloração diferencial de Gram, tolerância a $\mathrm{NaCl}$ a $7 \%$ e patogenicidade em cultivares de feijoeiro suscetíveis. Detectou-se a presença de Curtobacterium flaccumfaciens pv. flaccumfaciens em 23 amostras (62,2\%), indicando a importância das sementes como fonte de inoculo inicial.

Palavras-chave: Phaseolus vulgaris, murcha-de-curtobacterium, bactéria, patologia de sementes.

\begin{abstract}
Detection of Curtobacterium flaccumfaciens pv. flaccumfaciens in seeds of common bean produced in Santa Catarina

The presence of Curtobacterium flaccumfaciens pv. flaccumfaciens was evaluated in 37 common bean seed samples, of the black and carioca groups, produced in counties of Santa Catarina State, Brazil. The seeds were soaked and aliquots of the suspension formed were placed on the surface of the semi-selective medium MSCFF. Species identification was done by evaluation of the cell morphology, feature Gram test, feature tolerance to $7 \%$ of $\mathrm{NaCl}$ and pathogenicity tests. Curtobacterium flaccumfaciens pv. flaccumfaciens was detected in 23 samples (62.2\%), showing the importance of the seeds as source of inoculum.
\end{abstract}

Keywords: Phaseolus vulgaris, bacterial wilt, bacteria, seed pathology.

Historicamente, a produção de sementes fiscalizadas de feijoeiro em Santa Catarina tem atendido menos de $20 \%$ da área cultivada, havendo a prevalência do uso de sementes produzidas pelo próprio agricultor. Estas podem contribuir com a diminuição do rendimento do feijoeiro, pois não apresentam qualidade fisiológica satisfatória e podem estar em associação com diversos agentes fitopatogênicos.

Avaliando-se a sanidade de sementes de feijão utilizadas no Estado de Santa Catarina, de 1993 a 2003, constatou-se elevada incidência de fungos fitopatogênicos que sobrevivem no solo e prevalência de Aspergillus spp., Penicillium spp., Chaetomium spp. e Cladosporium spp. (Theodoro, 2005). Valarini \& Spadotto (1995) avaliaram a qualidade sanitária de sementes de feijoeiro no Brasil e detectaram Xanthomonas axonopodis pv. phaseoli em $8,0 \%$ das amostras analisadas, de um total de 25 lotes de sementes fiscalizadas/certificadas, coletadas na região de Guairá, SP, safra 1992/93. Torres (2001) avaliou a presença de $X$. axonopodis pv. phaseoli em 34 amostras de sementes de feijoeiro fiscalizadas, produzidas no Estado do Paraná, safras 1998/1999 e 1999/1999, e constatou a presença desta bactéria em $50 \%$ das amostras analisadas.

No Brasil, a murcha-de-curtobacterium, causada por Curtobacterium flaccumfaciens pv. flaccumfaciens (Hedges) Collins \& Jones, está presente em lavouras de feijão localizadas nos estados de Goiás, Paraná, Santa Catarina e São Paulo, além do Distrito Federal. Em território catarinense foi inicialmente constatada por Leite Jr. et al. (2001), no município de Campos Novos. Posteriormente, esta doença foi verificada em lavouras de feijão localizadas em Faxinal dos Guedes, Guatambu, Ipuaçu, Ponte Serrada e Tigrinhos (Theodoro \& Maringoni, 2006c), mas pode estar presente em outros municípios de Santa Catarina.

Embora exista uma intensa busca por métodos de controle da murcha-de-curtobacterium (Soares et al., 2004; Rodrigues et al., 2006; Theodoro \& Maringoni, 2006a; Theodoro \& Maringoni, 2006b), seu manejo está fundamentado no uso de cultivares resistentes, rotação de culturas e sementes sadias (Maringoni, 2002; Maringoni \& Camara, 2006; Maringoni et al., 2006). 
Apesar do controle genético ser recomendado para a murcha-de-curtobacterium do feijoeiro, nenhuma cultivar atualmente recomendada para Santa Catarina possui resistência a C. flaccumfaciens pv. flaccumfaciens (Theodoro \& Maringoni, 2006c). Por meio da avaliação da reação de 73 cultivares locais, coletadas em Santa Catarina, perante C. flaccumfaciens pv. flaccumfaciens, os genótipos 'Mouro Piratuba' (grupo de cores) e 'Vagem Amarela' (grupo carioca) foram identificados como fontes de resistência à murcha-de-curtobacterium, sendo indicadas como fontes de resistência em programas de melhoramento genético do feijoeiro (Theodoro et al., 2007).

Não existe um método oficial, indicado pelo Ministério da Agricultura, Pecuária e Abastecimento (MAPA), para a detecção de C. flaccumfaciens pv. flaccumfaciens em sementes de feijoeiro. Por meio do uso do meio de cultura MSCFF desenvolvido por Maringoni et al. (2006), houve a constatação da viabilidade de métodos qualitativos para a detecção de C. flaccumfaciens pv. flaccumfaciens em lotes de sementes de feijoeiro, em exames de rotina laboratorial. Foi detectada a presença desta bactéria em metade dos 30 lotes de sementes de feijoeiro avaliados e obtidos nos Estados de São Paulo, Paraná, Goiás e Rio Grande do Sul (Maringoni \& Câmara, 2006).

O presente trabalho teve como objetivo avaliar se $C$. flaccumfaciens pv. flaccumfaciens também está associada a sementes de feijoeiro produzidas em Santa Catarina e foi realizado no Laboratório de Fitossanidade do Centro de Pesquisa para Agricultura Familiar (Cepaf), da Epagri, em Chapecó, SC. Foram avaliadas 37 amostras de sementes, produzidas nos municípios de Cunhataí, Lajeado Grande, Palmitos e Chapecó. No laboratório, as amostras foram acondicionadas em sacos de papel, identificadas, fumigadas e armazenadas a temperatura ambiente.

Cada amostra foi subdividida em cinco sub-amostras de $200 \mathrm{~g}$ e cada uma delas foi transferida para frascos com $600 \mathrm{~mL}$ de água destilada. Os frascos foram fechados com tampões de algodão, incubados a $5^{\circ} \mathrm{C} / 24 \mathrm{~h}$ e, posteriormente, agitados manualmente. Retirou-se uma alíquota da suspensão do macerado com auxílio de alça de platina em aro, que foi transferida riscando-se, em zigue-zague, a superfície do meio de cultura semi-seletivo MSCFF (Maringoni \& Camara, 2006).

Cada sub-amostra foi representada por oito seções (quatro placas) e, com isso, obteve-se 40 seções por amostra de lotes de sementes. As placas foram incubadas a $28^{\circ} \mathrm{C}$, por 72-96h e foi observada a presença ou não de colônias típicas de C. flaccumfaciens pv. flaccumfaciens. As colônias suspeitas foram multiplicadas em meio nutriente líquido, com 7,0\% de $\mathrm{NaCl}$. Foram cultivadas cinco plântulas de feijoeiro, das cultivares, em vasos de aproximadamente $5 \mathrm{~L}$ de capacidade, para a realização do teste de patogenicidade. As sementes foram tratadas em solução de carbendazin + thiram $(0,15+0,35 \mathrm{~g}$ i.a./L), durante cinco minutos. A inoculação dos isolados bacterianos ocorreu aos 11 dias após a emergência e consistiu em duas punções no epicótilo de feijoeiros cv. Uirapuru, com uma alça reta embebida em colônias de C. flaccumfaciens pv. flaccumfaciens, cultivadas em meio de cultura nutriente-sacarose-ágar a $28^{\circ} \mathrm{C}$, por $48 \mathrm{~h}$ (Maringoni, 2002). Na testemunha foi usada água destilada e esterilizada e a avaliação dos sintomas ocorreu aos 21 dias após a inoculação. Fragmentos do caule das plantas com sintomas típicos de C. flaccumfaciens pv. flaccumfaciens foram transferidos em MSCFF. Após o desenvolvimento das colônias bacterianas, procederam-se testes de coloração diferencial de Gram e a repicagem dos isolados em nutriente líquido com $7 \%$ de $\mathrm{NaCl}$, para que houvesse a confirmação da identidade do microrganismo isolado, caso houvesse crescimento bacteriano.

As amostras foram consideradas infectadas quando apresentaram, em pelo menos uma seção da placa, uma colônia típica de C. flaccumfaciens pv. flaccumfaciens e o isolado foi patogênico ao feijoeiro. O resultado foi expresso quanto à presença ou não da bactéria nas amostras de sementes analisadas.

Foram avaliadas 37 amostras de sementes de genótipos de feijoeiro (Tabela 1), produzidas nas safras 2004/05 (2,7\%) e 2005/06 (97,3\%) nos municípios de Chapecó (29 amostras), Lajeado Grande (três amostras), Cunhataí (duas amostras) e Palmitos (três amostras). Dos genótipos avaliados, 5,4\% eram cultivares locais, 40,5\% linhagens e $54,0 \%$ cultivares comerciais, sendo que $48,6 \%$ eram do grupo preto e $51,4 \%$ do grupo carioca. As amostras de sementes comerciais ou produzidas localmente foram coletadas diretamente nos estabelecimentos rurais ou fornecidas por extensionistas da Epagri. Algumas amostras, especialmente de linhagens, foram disponibilizadas pela equipe do programa de melhoramento genético da Epagri/Cepaf(Tabela 1).

Detectou-se a presença de colônias, de $C$. flaccumfaciens pv. flaccumfaciens, patogênicas ao feijoeiro em 23 amostras (Tabela 1), representando 62,1\% de amostras infectadas. Das amostras infectadas, sete $(30,4 \%)$ foram de sementes do grupo de feijão preto e 16 do grupo carioca (69,6\%). Observou-se que $84,2 \%$ das 19 amostras do grupo carioca estavam infectadas, sendo que $62,5 \%$ eram linhagens e $37,5 \%$ cultivares comerciais.

Maringoni \& Camara (2006) detectaram $C$. flaccumfaciens pv. flaccumfaciens em 50\% das 30 amostras de sementes de feijoeiro coletadas em diversos estados produtores e afirmaram que o agente causal da murcha-decurtobacterium do feijoeiro está disseminado em lavouras localizadas em diversas regiões brasileiras. A percentagem de sementes de feijão do grupo carioca infectada por $C$. flaccumfaciens pv. flaccumfaciens foi maior em relação a percentagem detectada nas amostras do grupo preto e todos eles foram de lotes provenientes do município de Chapecó.

Detectou-se C. flaccumfaciens pv. flaccumfaciens em pelo menos uma amostra de sementes de feijoeiro dos genótipos IPR- Uirapuru, FT- Nobre, FT Bonito, IPR Juriti, Carioca e Pérola, suscetíveis à murcha-de-curtobacterium, enquanto que na amostra de sementes da 'SCS 202 - Guará', que possui níveis de resistência horizontal (Theodoro 
TABELA 1 - Detecção de C. flaccumfaciens pv. flaccumfaciens em amostras de sementes de feijoeiro produzidas em Santa Catarina

\begin{tabular}{|c|c|c|c|c|}
\hline Genótipos & Categoria $^{1}$ & Coloração dos grãos & Município & Resultado $^{2}$ \\
\hline Carioca & $\mathrm{CL}$ & Carioca & Cunhataí & - \\
\hline Preto & $\mathrm{CL}$ & Preto & Cunhataí & + \\
\hline IPR- Chopin & $\mathrm{CC}$ & Preto & Lajeado Grande & - \\
\hline IAPAR-81 & $\mathrm{CC}$ & Carioca & Lajeado Grande & - \\
\hline IPR- Uirapuru & $\mathrm{CC}$ & Preto & Lajeado Grande & - \\
\hline IPR- Uirapuru & $\mathrm{CC}$ & Preto & Chapecó & + \\
\hline IAPAR-81 & $\mathrm{CC}$ & Carioca & Palmitos & - \\
\hline Uirapuru & $\mathrm{CC}$ & Preto & Palmitos & + \\
\hline BRS- Campeiro & $\mathrm{CC}$ & Preto & Chapecó & - \\
\hline CHP 99-65 & $\mathrm{L}$ & Preto & Chapecó & - \\
\hline CHP 98-58 & $\mathrm{L}$ & Preto & Chapecó & - \\
\hline BRS - Expedito & $\mathrm{CC}$ & Preto & Chapecó & - \\
\hline CHP 97-04 & $\mathrm{L}$ & Preto & Chapecó & + \\
\hline IPR- Uirapuru & $\mathrm{CC}$ & Preto & Palmitos & + \\
\hline IPR- Graúna & $\mathrm{CC}$ & Preto & Chapecó & - \\
\hline CHP 97-01 & $\mathrm{L}$ & Preto & Chapecó & - \\
\hline FT- Bonito & $\mathrm{CC}$ & Carioca & Chapecó & + \\
\hline FT- Nobre & $\mathrm{CC}$ & Preto & Chapecó & + \\
\hline FT- Soberano & $\mathrm{CC}$ & Preto & Chapecó & - \\
\hline SCS 202- Guará & $\mathrm{CC}$ & Carioca & Chapecó & - \\
\hline IPR- Saracura & $\mathrm{CC}$ & Carioca & Chapecó & + \\
\hline CHP 98-59 & $\mathrm{L}$ & Preto & Chapecó & + \\
\hline IPR- Juriti & $\mathrm{CC}$ & Carioca & Chapecó & + \\
\hline CHC 98-42 & $\mathrm{L}$ & Carioca & Chapecó & + \\
\hline CHC 97-15 & $\mathrm{L}$ & Carioca & Chapecó & + \\
\hline CHC 98-51 & $\mathrm{L}$ & Carioca & Chapecó & + \\
\hline FAM. 03 & $\mathrm{~L}$ & Carioca & Chapecó & + \\
\hline CHC 97-28 & $\mathrm{L}$ & Carioca & Chapecó & + \\
\hline CHC 00-101 & $\mathrm{L}$ & Carioca & Chapecó & + \\
\hline CHC 98-27 & $\mathrm{L}$ & Carioca & Chapecó & - \\
\hline CHC 97-10 & $\mathrm{L}$ & Carioca & Chapecó & + \\
\hline CHC 98-61 & $\mathrm{L}$ & Carioca & Chapecó & + \\
\hline Carioca & $\mathrm{CC}$ & Carioca & Chapecó & + \\
\hline Rubi & $\mathrm{CC}$ & Carioca & Chapecó & + \\
\hline CHC 98-28 & $\mathrm{L}$ & Carioca & Chapecó & + \\
\hline Pérola & $\mathrm{CC}$ & Carioca & Chapecó & + \\
\hline IPR- Uirapuru & $\mathrm{CC}$ & Preto & Chapecó & + \\
\hline
\end{tabular}

${ }^{1}$ Categorias: Cultivar local (CL), comercial (CC) ou linhagem (L); ${ }^{2}$ Presença $(+)$ ou ausência (-) de Curtobacterium. flaccumfaciens pv. flaccumfaciens patogênicas ao feijoeiro, provenientes de isolamento no meio de cultura MSCFF.

\& Maringoni, 2006c), não foi detectada a presença do patógeno. Aventa-se a hipótese que cultivares suscetíveis podem exercer grande influência na infecção da semente.

Foram obtidos diversos isolados patogênicos ao feijoeiro, das diferentes amostras de sementes avaliadas e observou-se que houve variação na agressividade dos mesmos. Alguns isolados causaram, aos 10 dias após a inoculação, elevada severidade da doença nas plantas inoculadas. Por outro lado, plantas inoculadas com outros isolados apresentaram baixa severidade da doença, aos 21 
dias após a inoculação. Theodoro \& Maringoni (2006c) também verificaram indícios de variabilidade patogênica em oito isolados de C. flaccumfaciens pv.flaccumfaciens obtidas de plantas de feijoeiro cultivadas em Santa Catarina.

Constatou-se que somente a repicagem das colônias bacterianas suspeitas em $\mathrm{NL}+7 \% \mathrm{NaCl}$ não seria eficiente para detectar C. flaccumfaciens pv. flaccumfaciens com confiabilidade, pois houve o desenvolvimento de isolados bacterianos não patogênicos ao feijoeiro. Acredita-se que estas colônias foram de bactérias saprófitas e/ou de $C$. flaccumfaciens pv. flaccumfaciens não patogênicas. A presença de isolados de C. flaccumfaciens pv. flaccumfaciens não patogênicos, obtidos de sementes de feijoeiro, já foi relatada (Maringoni \& Câmara, 2006). Por meio dos resultados obtidos, pode-se indicar que o uso de sementes infectadas e/ou infestadas tem sido fonte de inóculo inicial da murcha-de-curtobacterium do feijoeiro, no Estado de Santa Catarina.

\section{REFERÊNCIAS BIBLIOGRÁFICAS}

Ito MF, Valarini PJ, Patrício FRA (1997) Detecção de Xanthomonas campestris pv. phaseoli e fungos em sementes de feijão produzidas no Estado de São Paulo. Summa Phytopathologica 23:118-121.

Leite Junior RP, Meneguim L, Behlau F, Rodrigues SR, Bianchini A (2001) Ocorrência de Curtobacterium flaccumfaciens subsp. flaccumfaciens em feijoeiro no Paraná e Santa Catarina. Fitopatologia Brasileira 26(Supl.):300-301.

Maringoni AC (2002) Comportamento de cultivares de feijoeiro comum à murcha-de-curtobacterium. Fitopatologia Brasileira 27:151-156.

Maringoni AC, Camara RC (2006) Curtobacterium flaccumfaciens pv. flaccumfaciens detection in bean seeds using a semi-selective culture medium. Brazilian Journal of Microbiology 37:451-455.

Maringoni AC, Camara RC, Souza VL (2006) Semi-selective culture medium for Curtobacterium flaccumfaciens isolation from bean seeds. Seed Science and Technology 34:117-124.

Rodrigues RB, Silva Júnior TAF, Maringoni AC (2006) Efeito da aplicação de lodo de esgoto na severidade da murcha-decurtobacterium em feijoeiro. Summa Phytopathologica 32:82-84.

Schuster ML (1959) Relation of root-knot nematodes and irrigation water to the incidence and dissemination of bacterial wilt of bean. Plant Disease Reporter 43:27-32.

Soares RM, Maringoni AC, Lima GPP (2004) Ineficiência de acibenzolar-s-methyl na indução de resistência de feijoeiro comum à murcha de curtobacterium. Fitopatologia Brasileira 29:373-377.

Theodoro GF (2005) Sanidade de sementes de feijoeiro em Santa Catarina, no período de 1993 a 2003. Agropecuária Catarinense $18: 72-76$

Theodoro GF, Maringoni AC (2006a) Efeito de doses de nitrogênio na severidade da murcha-de-curtobacterium em cultivares de feijoeiro comum. Summa Phytopathologica 32:131-138.

Theodoro GF, Maringoni AC (2006b) Efeito de doses de potássio na severidade da murcha-de-curtobacterium em cultivares de feijoeiro comum. Summa Phytopathologica 32:139-146.

Theodoro GF, Maringoni AC (2006c) Murcha-de-curtobacterium do feijoeiro no Estado de Santa Catarina e reação de genótipos a Curtobacterium flaccumfaciens pv. Alaccumfaciens. Summa Phytopathologica 32:34-41.

Theodoro GF, Herbes DH, Maringoni AC (2007) Fontes de resistência à murcha-de-curtobacterium em cultivares locais de feijoeiro, coletadas em Santa Catarina. Ciência e Agrotecnologia 31:1333-1339.

Torres JP (2006) Xanthomonas axonopodis pv. phaseoli em feijoeiro: sobrevivência em restos de cultura e ocorrência em sementes produzidas no Estado do Paraná. Tese de Doutorado. Universidade Estadual Paulista. Botucatu SP.

Valarini PJ, Spadotto CA (1995) Identificação de nichos de sobrevivência de fitopatógenos em áreas irrigadas de Guairá, SP. Pesquisa Agropecuária Brasileira 30:1239-1243. 